\title{
ANÁLISE DA FORMAÇÃO E ATUALIZAÇÃO DOS TÉCNICOS DE GINÁSTICA ARTÍSTICA DO ESTADO DE SÃO PAULO
}

\author{
Laurita Marconi Schiavon \\ Universidade Estadual Paulista "Júlio de Mesquita Filho" , Rio Claro, São Paulo, \\ Brasil
}

\section{Letícia Bartholomeu de Queiroz Lima}

Universidade Estadual Paulista "Júlio de Mesquita Filho" , Rio Claro, São Paulo, Brasil

\section{Maria Dilailça Trigueiro de Oliveira Ferreira}

Escola Superior de Tecnologia e Educação de Rio Claro, Rio Claro, São Paulo, Brasil

\section{Yara Machado da Silva}

Universidade Estadual Paulista "Júlio de Mesquita Filho" , Rio Claro, São Paulo, Brasil

\begin{abstract}
Resumo
A presente pesquisa qualitativa apresenta e discute a formação, a atualização e as experiências dos professores de Ginástica Artística (GA) relacionadas às suas atuações profissionais. Por meio de questionários foram coletadas informações de 57 técnicos da modalidade, de 18 cidades do interior do Estado de São Paulo. Os dados quantitativos foram analisados por estatística descritiva e os qualitativos por análise de conteúdo. Foi observado que ainda permanece uma lacuna entre a formação profissional e a atuação na GA em São Paulo, maior Federação de Ginástica do Brasil. A existência de uma formação específica na área se mostra necessária para a melhoria da qualidade da atuação dos profissionais e para a continuidade de resultados internacionais significativos.
\end{abstract}

Palavras chave: Ginástica. Prática Profissional. Esportes.

\section{Introdução}

A Ginástica Artística (GA) brasileira conquistou, na última década, importantes resultados em Campeonatos Mundiais e em Jogos Olímpicos. No entanto, é possível reconhecer em estudos, no mesmo período, no Brasil (NUNOMURA; CARRARA; CARBINATTO, 2013; NUNOMURA; NISTA-PICCOLO, 2003; NUNOMURA; OLIVEIRA, 2012; SCHIAVON et 
al., 2013), a necessidade de uma formação específica e da realização de atualizações para os profissionais que atuam com essa modalidade em nosso país.

Assim, a partir de questionamentos sobre a real situação da Ginástica Artística no Estado de São Paulo, surge a presente pesquisa que procura verificar se os profissionais da modalidade, de uma forma mais ampla, especializaram-se e buscaram maior conhecimento nessa área da mesma forma como avançaram os recentes resultados internacionais de atletas brasileiros. Para tal, investigamos a formação dos professores de Ginástica Artística do interior do Estado, as formas de atualização desses profissionais, suas experiências e necessidades.

São Paulo foi o Estado que mais investiu no desporto nos últimos dez anos (IBGE, 2003, 2009), e possui a Federação de Ginástica com maior número de entidades filiadas do Brasil (39 entidades), sendo a região Sudeste detentora de $40 \%$ das entidades brasileiras filiadas às Federações de ginástica no Brasil (SCHIAVON et al., 2013):

\begin{abstract}
Certamente essas concentrações são fruto de inúmeros fatores, dentre os quais os de ordem histórica e cultural da prática da Ginástica. Além disso, o início de sua prática institucionalizada ocorreu na região Sul e as primeiras Federações no país foram fundadas nas regiões Sul e Sudeste (RS, SP e RJ), fatos que colaboraram para o desenvolvimento privilegiado da ginástica. (SCHIAVON et al., 2013, p.426).
\end{abstract}

Além de ser um Estado representativo, do ponto de vista de entidades filiadas, especialmente no interior paulista há muitos campeonatos de massificação de Ginástica Artística, assim como competições regionais, estaduais e nacionais, envolvendo um número considerável de participantes da modalidade. Os Jogos Regionais e Jogos Abertos do Interior são competições em nível regional que motivam as cidades paulistas e seus jovens atletas a competirem. Grandes atletas brasileiros, como Daniele Hypólito, Laís Souza e Arthur Zanetti iniciaram aí as suas primeiras participações.

A demanda por resultados cada vez mais significativos faz com que, consequentemente, haja uma procura por profissionais especializados, cujo nível de conhecimento seja compatível com esta necessidade.

Atualmente, no Brasil, a formação de profissionais dessa área ocorre somente por meio dos cursos de graduação: Bacharelado em Educação Física, em Esporte ou em Ciências do Esporte. Mas será que todos os profissionais que atuam nesta modalidade passaram por disciplinas que tratem da GA? Será que a formação inicial recebida ofereceu subsídios necessários 
para a atuação na modalidade? Onde os profissionais estão se atualizando? Quais as suas necessidades nesse aspecto?

Vários autores (BARBOSA, 1999; NUNOMURA; CARRARA; CARBINATTO, 2013; NUNOMURA; NISTA-PICCOLO, 2003; PAOLIELLO, 2001; SCHIAVON, 2003; THOMAZZO, 2006) relatam uma carência na formação e na atualização dos profissionais de GA no Brasil. Nunomura (2001), em investigação com técnicos brasileiros, observou uma grande lacuna entre a formação acadêmica (graduação) e o campo de atuação, assim como um interesse por cursos mais específicos na área com conteúdos não contemplados durante a formação inicial. Barbosa-Rinaldi (2004) percebeu também que, na graduação, os alunos não estão sendo preparados para que possam desenvolver, quando profissionais, seus conhecimentos da forma adequada, pois além de as disciplinas de Ginástica não permitirem abordar os diferentes campos de atuação da mesma, há uma necessária reestruturação do currículo com as disciplinas gímnicas.

Nesse sentido, também Almeida (2012), ao observar os conteúdos presentes nas ementas das disciplinas relacionadas à Ginástica, verificou que, apesar de essas modalidades estarem presentes nos currículos dos cursos de Licenciatura em Educação Física, os conhecimentos ali adquiridos não são suficientes para que esse tema venha a ser abordado, sequer no contexto escolar.

Assim, a presente pesquisa buscou verificar a formação e atualização dos profissionais de Ginástica Artística, assim como suas experiências e necessidades na atuação com a modalidade.

\section{Procedimentos Metodológicos}

A abordagem metodológica adotada para esta pesquisa qualitativa foi de caráter descritivo, com dados quantitativos e qualitativos. Segundo Thomas e Nelson (2002), a importância da pesquisa descritiva fundamenta-se na premissa de que os problemas podem ser encontrados e resolvidos, bem como as práticas podem ser melhoradas por meio de observação, análise e descrição objetivas e completas. Desse modo, o uso de questionário configura-se como uma boa ferramenta de exploração do que se deseja conhecer no concernente a uma área, como é o caso do interior do Estado de São Paulo, neste presente trabalho.

\section{Amostra}

A amostra consistiu em profisssionais de Educação Física de "escolas e/ou centros de treinamento de Ginástica Artística" de prefeituras municipais e de clubes que desenvolvem a modalidade em cidades com população 
acima de 100.000 habitantes - de acordo com o censo 2009 (IBGE) do interior do Estado de São Paulo - participantes dos Jogos Regionais de 2011.

Fizeram parte deste estudo 57 técnicos(as)/professores(as) (34 mulheres e 23 homens) de Ginástica Artística (GA) pertencentes a 30 instituições de 18 cidades do interior do Estado de São Paulo (100\% do universo da pesquisa nos critérios estabelecidos).

A escolha das cidades com mais de 100.000 habitantes deve-se, primeiramente, ao fato de elas terem condições para uma infraestrutura esportiva suficiente para apoiar uma modalidade que necessita de equipamentos e de espaço com investimento financeiro significativo.

Segundo o IBGE (2009, p.66), no resultado das "Pesquisas de informações básicas Municipais - Perfil dos municípios brasileiros", a gestão do esporte é influenciada pelo porte populacional dos municípios, ressaltando que "naqueles de menor poder de arrecadação fiscal, o montante das despesas necessárias à gerência da atividade, muitas vezes, inviabiliza a criação e a manutenção de estrutura mais robusta com esta finalidade". Essa mesma pesquisa divide as classes de tamanho de município da seguinte forma: até 5.000 habitantes / 5.001 a $20.000 / 20.001$ a $50.000 / 50.001$ a $100.000 /$ 100.001 a 500.000 , e acima de 500.000 habitantes.

$\mathrm{O}$ investimento em esporte e a estrutura organizacional da gestão do esporte nas cidades a partir de 100.001 habitantes é surpreendentemente superior, com um salto qualitativo significativo, o qual será utilizado como referência para as cidades pesquisadas (IBGE, 2009).

Além do aspecto populacional (cidade a partir de 100.001 habitantes), o segundo critério exigido foi a cidade ter participado na modalidade Ginástica Artística nos Jogos Regionais do Interior do Estado de São Paulo em 2011. Este campeonato é realizado por regiões do Estado e possibilita a participação das cidades em qualquer modalidade esportiva, sem precisar apresentar índices ou classificações para tal.

\section{Instrumentos e Procedimentos}

Para a coleta dos dados foi utilizado um questionário estruturado com perguntas abertas e fechadas, pertinentes aos objetivos da pesquisa, o qual foi enviado para ser preenchido por cada técnico(a)/professor(a) de Ginástica Artística formado, de cada instituição. Por meio desse questionário, foram levantadas informações a respeito da formação acadêmica e complementar desses profissionais e as suas opiniões sobre os aspectos que poderiam auxiliar no aprimoramento da sua capacidade profissional.

\section{Análise de Dados}

Pensar a Prática, Goiânia, v. 17, n. 3, p. 618-635, jul./set. 2014 
Os dados foram tratados por estatística descritiva e por análise de conteúdo que compreende "um conjunto de técnicas de análise das comunicações, que utiliza procedimentos sistemáticos e objetivos de descrição do conteúdo das mensagens" (BARDIN, 2010, p.38). De acordo com a mesma autora, a análise passa por três polos cronológicos: 1) pré-análise; 2) exploração do material; 3) tratamento dos resultados, a inferência e a interpretação.

A pré-análise é a fase de organização, cujo objetivo é sistematizar as ideias para torná-las operacionais e assim esquematizar o desenvolvimento das operações sucessivas no plano de análise. Na exploração do material, os dados são codificados e sistematizados para a próxima fase, na qual os resultados e a interpretação são tratados para serem significados e validados, de forma que sejam categorizados por meio de inferências e interpretações (BARDIN, 2010).

\section{Resultados e Discussões}

Da totalidade da amostra, apenas $10 \%$ dos profissionais inseridos na pesquisa disseram trabalhar somente com a iniciação, e 1,75\% com o treinamento, dados que confirmam o cenário nacional da Ginástica Artística: poucas pessoas especializadas na modalidade, ou seja, os mesmo profissionais são responsáveis tanto pela iniciação, etapas de preparação preliminar e etapa de especialização inicial, como pelas etapas de especialização aprofundada e de resultados superiores de ginastas (ZAKHAROV; GOMES, 2003).

Ao analisar as respostas dos profissionais, não foram observadas diferenças significativas entre os $10 \%$ que apenas trabalham com a iniciação, desta forma, os dados serão apresentados de maneira unificada.

\section{Tabela 1: Tempo de Atuação dos Técnicos}

\begin{tabular}{|c|c|c|}
\hline Tempo de Atuação & Frequência Absoluta & $\begin{array}{c}\text { Frequência } \\
\text { Relativa }\end{array}$ \\
\hline Mais de 20 anos & 18 & $32 \%$ \\
\hline 15 a 20 anos & 5 & $9 \%$ \\
\hline 11 a 15 anos & 7 & $12 \%$ \\
\hline 5 a 10 anos & 16 & $28 \%$ \\
\hline 3 a 5 anos & 7 & $12 \%$ \\
\hline Menos de 2 anos & 4 & $7 \%$ \\
\hline
\end{tabular}

Ao observar o tempo de atuação dos técnicos, é possível constatar que $81 \%$ dos profissionais têm atuado há pelo menos cinco anos, e que 53\% 
trabalham com a modalidade há mais de 11 anos, sendo $32 \%$ há mais de 20 anos, o que nos possibilita interpretar que estamos tratando com profissionais experientes na área.

Tabela 2: Formação acadêmica dos profissionais

\begin{tabular}{lcc}
\hline \multicolumn{1}{c}{ Formação Geral } & $\begin{array}{c}\text { Frequência Ab- } \\
\text { soluta }\end{array}$ & $\begin{array}{c}\text { Frequência } \\
\text { Relativa }\end{array}$ \\
\hline Graduação & 20 & $35 \%$ \\
Graduação e uma Especialização & 26 & $46 \%$ \\
Graduação e mais de uma Especialização & 5 & $9 \%$ \\
Graduação e Mestrado & 6 & $10 \%$ \\
\hline
\end{tabular}

\section{Tabela 3: Disciplina de Ginástica Artística Durante a Graduação}

\begin{tabular}{lcc}
\hline Disciplina de GA na Graduação & $\begin{array}{c}\text { Frequência } \\
\text { Absoluta }\end{array}$ & $\begin{array}{c}\text { Frequência } \\
\text { Relativa }\end{array}$ \\
\hline SIM & 53 & $93 \%$ \\
NÃO & 4 & $7 \%$ \\
\hline
\end{tabular}

Todos(as) os(as) técnicos(as)/professores(as) presentes neste estudo possuem graduação em Educação Física, inclusive essa é uma exigência da Confederação Brasileira de Ginástica e das Federações Estaduais de Ginástica, juntamente com a inscrição no Conselho Regional de Educação Física para cadastro de técnicos/as.

De todos os sujeitos, 93\% afirmaram ter cursado disciplinas com conteúdos relacionados à GA durante a graduação, ou seja, é suposto que deveriam possuir conhecimentos ao menos para uma atuação básica na área. Porém, em estudo realizado por Nunomura e Nista-Piccolo (2003) em relação à disciplina de GA no curso de graduação, as autoras levantaram que $40 \%$ dos técnicos entrevistados mostraram-se insatisfeitos e 33,33\% parcialmente satisfeitos com a disciplina. Isso leva a concluir que nossos(as) técni$\cos ($ as), em sua maioria, não saíram da graduação satisfeitos com a sua preparação e, por conta disso, sentiram a necessidade de procurar outras fontes de conhecimento.

Este cenário vai ao encontro dos dados de que $65 \%$ dos(as) técnicos(as)/professores(as) buscaram complementar suas formações em cursos de pós-graduação, revelando, assim, interesse em se aprimorar e falta de acomodação como profissionais. 
Tabela 4: Experiências Anteriores com a Ginástica Artística

\begin{tabular}{lcc}
\hline \multicolumn{1}{c}{ Categorias } & $\begin{array}{c}\text { Frequência } \\
\text { Absoluta }\end{array}$ & $\begin{array}{c}\text { Frequência } \\
\text { Relativa }^{1}\end{array}$ \\
\hline Ex-atleta/Praticante & 40 & $70,17 \%$ \\
Estágio na Modalidade & 24 & $42,10 \%$ \\
Árbitro & 20 & $35,08 \%$ \\
Curso de Graduação & 6 & $10,52 \%$ \\
Nenhuma & 3 & $5,26 \%$ \\
\hline
\end{tabular}

Tabela 5: Razões que levaram os profissionais para a Ginástica Artística

\begin{tabular}{llcc}
\hline \multicolumn{1}{c}{ Categorias } & $\begin{array}{c}\text { Frequência Ab- } \\
\text { soluta }\end{array}$ & $\begin{array}{c}\text { Frequência } \\
\text { Relativa }^{2}\end{array}$ \\
\hline $\begin{array}{l}\text { Gosto/Interesse pela modalidade e suas } \\
\text { características }\end{array}$ & 32 & $56,41 \%$ \\
$\begin{array}{l}\text { Experiência prática prévia } \\
\text { modalidade }\end{array}$ & com a & 29 & $50,87 \%$ \\
$\begin{array}{l}\text { Oportunidade de trabalho } \\
\text { Influência externa }\end{array}$ & 12 & $21,05 \%$ \\
Árbitro & 11 & $19,29 \%$ \\
\hline
\end{tabular}

Em relação às experiências prévias com a modalidade, grande parte dos(as) técnicos(as)/professores(as) $(70,17 \%)$ disse já ter praticado GA, o que nos faz ver que essa experiência anterior como atleta ou mesmo como praticante parece ser um fator importante para a atuação como técnico(a), pois, ao relatarem as razões que os(as) levaram para a Ginástica Artística, $50,87 \%$ disseram ser por experiência prática prévia com a modalidade. Esses resultados vão de encontro ao observado em outros estudos (CARBINATTO et al, 2010; NUNOMURA; NISTA-PICCOLO, 2003; NUNOMURA, 2001; TSUKAMOTO, 2009).

De acordo com Lemyre, Trudel e Durand-Bush (2007), este tipo de experiência gera um conhecimento básico da modalidade como regras, téc-

Era possível assinalar mais de uma alternativa.

Era possível assinalar mais de uma alternativa.

Pensar a Prática, Goiânia, v. 17, n. 3, p. 618-635, jul./set. 2014 
nica de algumas habilidades que porventura precisem ser demonstradas, além do fato de terem observado técnicos em ação por muitos anos.

Outro percentual significativo da Tabela 5, o "Gosto/Interesse pela modalidade e suas características" (56,41\%) está também relacionado à experiência anterior como atleta, assim como é possível verificar no Quadro 1, com aprofundamento nessa categoria.

\section{Quadro 1: Gosto pela modalidade e por suas características}

\begin{tabular}{|c|c|}
\hline Categoria & Unidade de registro \\
\hline $\begin{array}{l}\text { Gosto/ Interes- } \\
\text { se pela } \\
\text { modalidade e } \\
\text { suas caracterís- } \\
\text { ticas }\end{array}$ & $\begin{array}{l}\text { P3: Paixão pela modalidade. } \\
\text { P4: Gosto pela modalidade. } \\
\text { P5: } 25 \text { anos como atleta }{ }^{3}-13 \text { na seleção nacional/ amor pela gi- } \\
\text { nástica. } \\
\text { P8: Ex-ginasta. Sempre gostei muito, caminho natural. } \\
\text { P9: Ex-ginasta pioneira na cidade, gosto pela modalidade. } \\
\text { P10: Amor pelo esporte, paixão pela ginástica, sonhos e ideais. } \\
\text { P14: Admiração, desafio. E principalmente por ser um esporte de } \\
\text { formação que serve de base para qualquer outro esporte. } \\
\text { P15: Ser ex-ginasta, pelos desafios da modalidade. } \\
\text { P16: Por ser um esporte diferente, pela plasticidade e por já ter } \\
\text { parentes praticantes. } \\
\text { P18: Sempre amei, desde a Nadia Comanecci, sempre quis ver e } \\
\text { fazer, mas minha cidade não tinha GA. Então eu iniciei a modali- } \\
\text { dade na cidade, me apaixonei e hoje continuo, mas com outra vi- } \\
\text { são, mais voltada para educação, esporte, saúde e cidadania. } \\
\text { P19: O contato com a disciplina na época da graduação; a pos- } \\
\text { sibilidade de desenvolver o trabalho em minha cidade; o interes- } \\
\text { se pelas particularidades e complexidade da modalidade. } \\
\text { P21: Curiosidade de como ensinar, desafio de ensinar acrobacias } \\
\text { e coreografias, escassez de profissionais no mercado, receptivi- } \\
\text { dade dos profissionais que já atuam. } \\
\text { P22: Inicialmente pela necessidade de professor por parte da } \\
\text { prefeitura e depois por grande afinidade e interesse. } \\
\text { P26: A beleza dos movimentos, a qualidade de vida e alguma ex- } \\
\text { periência esportiva. } \\
\text { P27: Desde os cinco anos de idade pratico a modalidade, desde } \\
\text { então apenas dei continuidade no esporte no qual sou apaixona- } \\
\text { da (fazem } 25 \text { anos). } \\
\text { P28: Sou ex-ginasta e apaixonada pela modalidade. }\end{array}$ \\
\hline
\end{tabular}

3 Grifos nossos

Pensar a Prática, Goiânia, v. 17, n. 3, p. 618-635, jul./set. 2014 


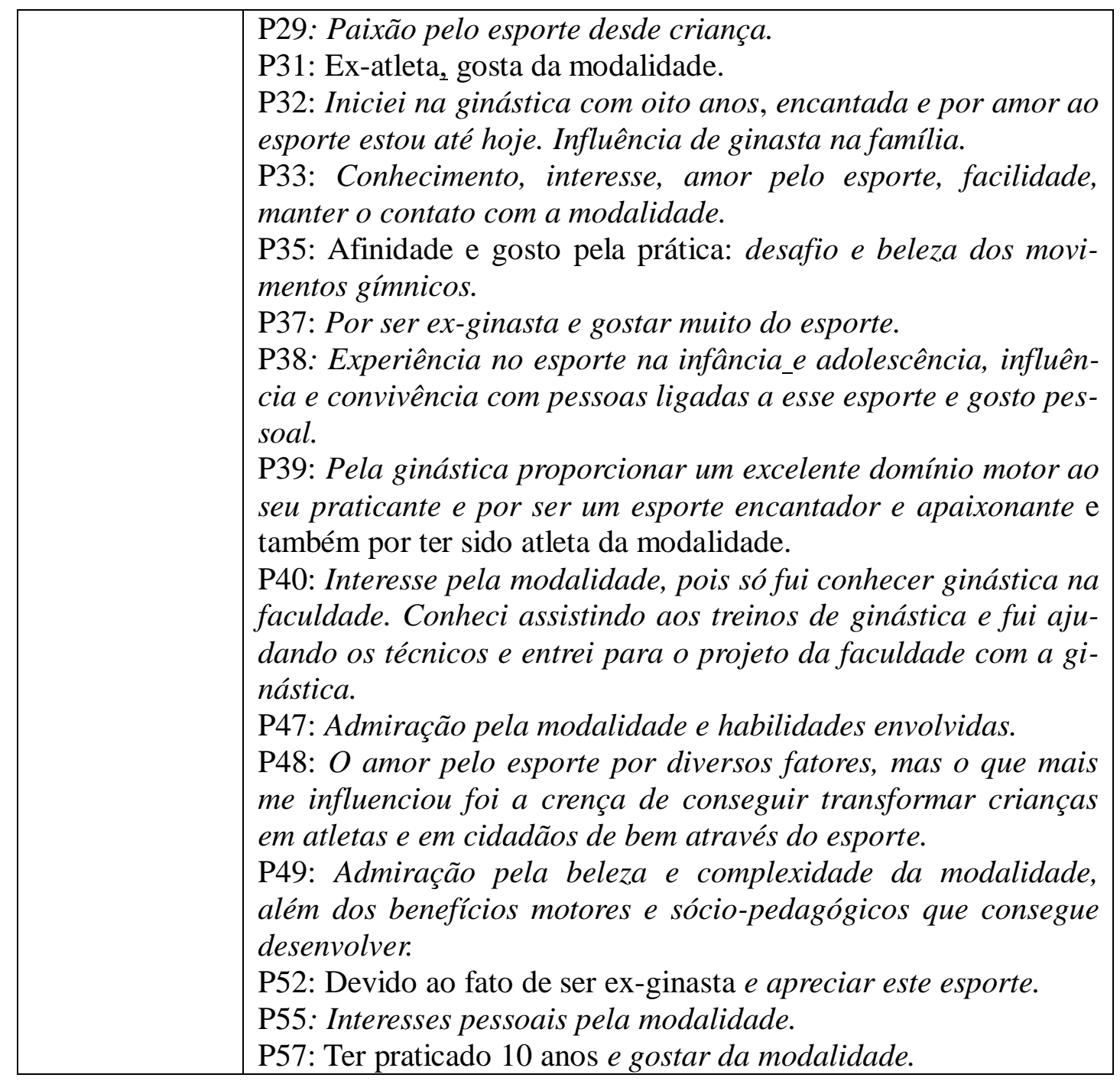

Se a experiência prática tem um impacto significativo na atuação do profissional, como apontado anteriormente, será que as aulas da graduação também lhe foram estimulantes? Apenas $10,52 \%$ relatam terem sido motivados a trabalhar com a GA por experiência prévia na graduação. Segundo Tsukamoto (2009, p. 5), esse fato pode estar associado ao processo de formação acadêmica dos profissionais durante a graduação, pois:

[...] as disciplinas práticas, especialmente as disciplinas ginásticas, muitas vezes são encaradas pelos alunos e desenvolvidas pelos professores na perspectiva da prática somente, e não de uma prática reflexiva que visa preparar aquele que, no futuro irá ensinar. (Tsukamoto, 2009, p. 5.) 
Assim, além de não despertarem o interesse para esta área de atuação, as aulas não incitam reflexões para que os estudantes que já tiveram contato prévio com a modalidade, como atletas ou praticantes, modifiquem suas perspectivas e suas formas de atuação quando retornam aos ginásios.

A dimensão apenas prática não evidencia ao aluno um acréscimo de conhecimento, pois o aprendido muitas vezes coincide somente com o que foi proporcionado durante sua vida esportiva; e, para aqueles que não possuem contato prévio, a perspectiva não contribui de forma efetiva para uma futura atuação (THOMMAZO, 2006).

Apesar da formação durante a graduação ser o caminho pelo qual todos os técnicos têm que passar para chegar ao mercado de trabalho, muitos não o consideram como tendo sido o meio mais eficiente de aprendizado, principalmente devido à sua pequena carga horária (WERTHNER; TRUDEL, 2006). Este fato tem uma enorme influência nos dias de hoje, pois podemos observar diversos técnicos que foram atletas reproduzindo suas próprias experiências - positivas ou negativas - e, muitas vezes, sem fundamentação ou reflexão.

\section{Tabela 6: Participação em Cursos Específicos}

\begin{tabular}{lcc}
\hline \multicolumn{1}{c}{ Cursos Específicos } & Frequência Absoluta & $\begin{array}{c}\text { Frequência } \\
\text { Relativa }\end{array}$ \\
\hline SIM & 48 & $84 \%$ \\
Ñ̃O & 9 & $16 \%$ \\
\hline
\end{tabular}

Tabela 7: Participação em Simpósios e Congressos

\begin{tabular}{lcc}
\hline Simpósios e Congressos & Frequência Absoluta & $\begin{array}{c}\text { Frequência } \\
\text { Relativa }\end{array}$ \\
\hline SIM & 27 & $47 \%$ \\
NÃO & 30 & $53 \%$ \\
\hline
\end{tabular}

Constatamos que, para intervir na lacuna deixada pelos cursos de graduação, cada vez mais os profissionais buscam aprimorar sua formação, especialmente no que se refere aos conhecimentos específicos para uma melhor atuação: $84 \%$ dos(as) técnicos(as)/professores(as) afirmam participar de cursos específicos da área. Se, por um lado, os profissionais procuram se atualizar por meio de cursos específicos, por outro, a participação deles em simpósios e congressos não é significativa, somente $47 \%$ deles dizem tê-los frequentado.

Segundo Carbinatto (2010) e colaboradores, poucos(as) técnicos(as)/professores(as) têm algum contato ou parceria com universidades e/ou centros de 
pesquisas, o que levou os autores a duas preocupações: o técnico não procura a universidade ou os pesquisadores não buscam parcerias com técnicos e centros de treinamento. Ainda nos dias de hoje podemos observar um distanciamento entre as pesquisas científicas e sua aplicação prática, o que faz com que muitos conhecimentos não sejam de fato aplicados, dificultando o desenvolvimento completo dos nossos atletas e da modalidade no país (BORTOLETO, 2012). A relação distante entre os órgãos que administram o esporte, os centros de treinamento e de pesquisa no Brasil não conduzem esforços no sentido de um aprimoramento da GA brasileira (SCHIAVON, 2009).

O conhecimento científico, em sua abrangência, auxilia na reestruturação, na constante evolução e no entendimento das necessidades da modalidade. Assim, um acompanhamento científico se torna essencial, pois, dessa forma, os profissionais da área teriam um apoio didático para suas fundamentações (NUNOMURA; NISTA-PICCOLO, 2003). No entanto, os pesquisadores precisam estar atentos às necessidades dos(as) técnicos(as) e não apenas às da universidade, retornando resultados de pesquisa de forma mais rápida e didática, o que pode aproximar os técnicos dos centros de pesquisa.

Esta afirmação é corroborada por Williams e Kendall (2007) que discutem que esse distanciamento se deve às diferenças entre as atividades dos técnicos e o foco das pesquisas na área do esporte e que, geralmente, as pesquisas não vão de encontro àquilo que os técnicos precisam. Na presente pesquisa, apenas $7 \%$ dos(as) profissionais consideram que uma aproximação com a universidade poderia melhorar a qualificação profissional deles (Tabela 8).

A utilização de pesquisas nos ginásios é essencial para o desenvolvimento tanto dos técnicos como dos pesquisadores, sendo urgente uma maior integração entre as partes interessadas. Assim, é de suma importância a disseminação do conhecimento em eventos e em revistas aos quais os técnicos tenham maior acesso. Há de se salientar também a preocupação com a linguagem nesses veículos para que ela possa ser facilmente compreendida (WILLIAMS; KENDALL, 2007).

Segundo Bortoleto (2012), torna-se indispensável uma estrutura organizacional direcionada para uma maior e melhor integração entre o campo prático, científico e as respectivas entidades de organização estadual e nacional da modalidade visando ações mais eficientes. Apesar desse distanciamento entre os(as) pesquisadores(as) e técnicos(as), a presente pesquisa revela o interesse dos sujeitos por cursos e por complementações na área, conforme expõe a Tabela 8. 
Tabela 8: Componentes que poderiam melhorar a sua qualidade profissional $^{4}$

\begin{tabular}{lcc}
\hline \multicolumn{1}{c}{ Categorias } & $\begin{array}{c}\text { Frequência } \\
\text { Absoluta }\end{array}$ & $\begin{array}{c}\text { Frequência } \\
\text { Relativa }\end{array}$ \\
\hline Cursos Específicos e Complementações & 38 & $66,66 \%$ \\
Integração de Informação/Intercâmbio & 15 & $26,31 \%$ \\
Infraestrutura & 15 & $26,31 \%$ \\
Apoio e Investimento & 12 & $21,05 \%$ \\
Valorização do Profissional e da Modalidade & 5 & $8,77 \%$ \\
Maior Número de Praticantes & 4 & $7,01 \%$ \\
Aproximação com Universidades & 4 & $7,01 \%$ \\
Trabalho Interdisciplinar & 3 & $5,26 \%$ \\
\hline
\end{tabular}

Segundo Nunomura e Nista-Piccolo (2003), muitos(as) técnicos(as) mostram-se insatisfeitos(as) por não encontrarem meios de aprimorar seus conhecimentos dentro do próprio país. No Brasil são raros os cursos de pósgraduação em GA e os cursos específicos da modalidade são muito escassos. Em decorrência disso, pudemos observar que alguns(as) técnicos(as) buscam conhecimento em outros países, como Estados Unidos, Dinamarca e Cuba. Além disso, aqui não há formação específica para os(as) profissionais que desejam seguir a carreira de técnico de GA.

De acordo com Nunomura (2004), no contexto internacional a situação é bem diferente, pois em países como Estados Unidos, Canadá, Portugal e Austrália há programas específicos para a formação desses profissionais juntamente com as respectivas Federações e Confederações, ou seja, eles não dependem apenas dos conhecimentos agregados durante a graduação.

Outro fato citado é a falta de integração e de intercâmbio com outros(as) técnicos(as) e/ou instituições $(26,31 \%)$, pois a união e a troca de informações e experiências, tanto positivas como negativas, poderiam facilitar o andamento da atuação. Segundo Lemyre, Trudel e Durand-Bush (2007), é justamente isso que acontece quando há interação com outros técnicos, pois o processo de aprendizado e o desenvolvimento de conhecimento são feitos de forma progressiva e interativa entre eles.

$4 \quad$ Era possível assinalar mais de uma alternativa.

Pensar a Prática, Goiânia, v. 17, n. 3, p. 618-635, jul./set. 2014 
Também podemos observar a falta de apoio e de investimento na modalidade como um elemento de influência na qualidade da atuação desses profissionais. A GA é uma modalidade que ainda requer muito incentivo do setor público e privado, e das próprias Federações e Confederações de ginástica do país. Na oportunidade de complementação da questão sobre "componentes que poderiam melhorar sua qualificação profissional", o técnico P25 revela que:

Como profissional venho investindo na minha formação, porém na área da ginástica não existem investimentos nem valorização dos profissionais e muito menos do esporte, por isso a maioria acaba trocando de profissão.

Outros técnicos chegam a citar que "o desinteresse é total pela modalidade, estar na ginástica é fim de carreira” (P24). Isso afirma também o técnico P29:

Falta incentivo, apoio e estrutura. Estou no esporte por amor, porque qualquer outro 'trabalho' tem mais reconhecimento, se ganha mais dinheiro. Tenho vergonha de colocar esta fala, mas estudei por quatro anos e não existe reconhecimento.

$\mathrm{Na}$ Tabela 5 é possível verificar que apenas $21,05 \%$ optaram pelo trabalho com a modalidade destacando-a como "oportunidade de trabalho".

A falta de infraestrutura também parece ser um fator de influência no desempenho profissional $(26,31 \%)$. Ainda, mesmo com uma maior divulgação da modalidade e com melhores resultados nos últimos anos, o Brasil tem uma carência de materiais de qualidade para o melhor desenvolvimento da GA, o que pode dificultar na conquista de resultados expressivos internacionalmente e desestimular futuros talentos e profissionais da área. De acordo com Nunomura e Oliveira (2012), a infraestrutura de treinamento é um dos pilares para o sucesso no esporte. Segundo eles, sem condições ideais de treinamento, as chances de sucesso são restritas ou até improváveis.

Em um estudo realizado por Schiavon e Paes (2012) com dez ginastas que representaram o Brasil em Jogos Olímpicos, foi verificado que todas as atletas, em algum momento de suas carreiras, passaram por condições inapropriadas de ginásios e equipamentos durante seus treinamentos na GA. Esse aspecto está diretamente relacionado com a "falta de um maior número de praticantes" (7,01\%), outro fator citado pelos(as) técnicos(as), ou seja, a falta de locais e materiais apropriados para um treinamento adequado dificulta uma maior divulgação e a disseminação da modalidade. 
Por fim, ainda sobre o aspecto de infraestrutura, verificamos que alguns técnicos sentem a necessidade de um trabalho interdisciplinar. No Brasil são raros os técnicos que desfrutam de uma equipe multidisciplinar formada, por exemplo, por nutricionista, psicólogo, fisioterapeuta, médico, entre outros. Na maioria das vezes essas diversas funções recaem sobre o(a) próprio(a) técnico(a) (SCHIAVON, 2009).

A dificuldade de formação específica ou a procura por atualização em Ginástica Artística perpassam por diversos fatores, pois não se trata apenas de cursos específicos de formação, mas também da valorização do profissional e de condições mínimas de trabalho.

\title{
Considerações Finais
}

Todos no meio do esporte sabem da importância do papel dos técnicos para o desenvolvimento de qualquer que seja a modalidade. Desta forma, sua formação e sua atualização específicas para a modalidade, além da graduação em Educação Física, tornam-se primordiais para tal. No caso da GA no Brasil, como pudemos observar, a graduação não supre as necessidades da modalidade competitiva, e os meios para desenvolver uma formação específica para a modalidade são escassos.

Este cenário parece favorecer apenas aqueles profissionais que foram ginastas, pois essa experiência lhes propiciou um conhecimento específico e a oportunidade de conviver com outros técnicos. Entretanto, ao mesmo tempo em que foram beneficiados por essa vivência, há o risco de eles não refletirem sobre a prática desenvolvida como ginastas e o resultado ser a repetição dos mesmos métodos e culturas dos ginásios, como uma cultura familiar, que passa de pai para filho. Por outro lado, outros profissionais que não foram atletas podem não se sentir seguros em adentrar em um contexto esportivo pouco conhecido e com muitas particularidades.

Assim, tornam-se necessárias e fundamentais a obtenção e a implantação de programas específicos voltados para tal modalidade não só para aprofundar os conhecimentos técnicos, mas também para possibilitar reflexões sobre um processo que considere as condições ideais tanto para os(as) técnicos(as), quanto para os(as) ginastas em nosso país.

\section{ANALYSIS OF EDUCATION AND UPDATING OF ARTISTIC GYMNAS- TIC COACHES IN THE STATE OF SÃO PAULO}

\begin{abstract}
This qualitative research presents and discusses the education, updating and experiences of Artistic Gymnastic coaches related to their professional activities. Through
\end{abstract}

Pensar a Prática, Goiânia, v. 17, n. 3, p. 618-635, jul./set. 2014 
questionnaires, was collected information from 57 coaches of 18 cities in the State of São Paulo. The quantitative data were analyzed by descriptive statistics and the qualitative one by content analysis. It was observed that still remain a gap between professional education and activities in Artistic Gymnastics in São Paulo, the largest Gymnastic Federation of Brazil. The existence of a specific education on this area appears necessary to improve the quality of professional activities and to continuity of significant international results.

Keywords: Gymnastics. Professional Practice. Sports.

\section{ANÁLISIS DE LA FORMACIÓN Y ACTUALIZACIÓN DE ENTRENADORES DE GIMNASIA ARTÍSTICA DEL ESTADO DE SÃO PAULO}

\section{Resumen}

La presente investigación presenta y discute la formación, actualización y las experiencias de los profesores de Gimnasia Artística (GA) relacionadas a la actuación profesional de los mismos. Por medio de cuestionarios fueron colectadas informaciones de 57 técnicos de GA, de 18 ciudades del Estado de San Pablo. Los datos cuantitativos fueron analizados por estadística descriptiva y los cualitativos por análisis de contenido. Fue observado que todavía permanece una laguna entre la formación profesional y la actuación en GA en San Pablo, mayor Federación de Gimnasia de Brasil. La existencia de una formación específica en el área se muestra necesaria para la mejora de la calidad de la actuación de los profesionales y continuidad de resultados internacionales significativos.

Palabras-claves: Gimnasia. Práctica Profesional. Desportes.

\section{Referências}

ALMEIDA, E. X. A Ginástica na Formação de Licenciados em Educação Física. 2012. 174f. Dissertação (Mestrado em Educação Física) - Universidade São Judas Tadeu, São Paulo, 2012.

ARAÚJO, C. Manual de Ajudas em Ginástica. Porto Alegre: ULBRA, 2003.

BARDIN, L. Análise de Conteúdo. Lisboa: Edições 70, 2010

BARBOSA, I. P. A Ginástica nos cursos de licenciatura em Educação Física do Estado do Paraná. Tese (Mestrado) - Faculdade de Educação Física, Universidade Estadual de Campinas, Campinas, 1999.

BARBOSA-RINALDI, I. P. A ginástica como área de conhecimento na formação profissional em educação física: encaminhamentos para uma es- 
truturação curricular. 2004. 220 fls. Tese (Doutorado em Educação Física) Faculdade de Educação Física. Universidade Estadual de Campinas. Campinas-SP, 2004.

BORTOLETO, M. A. C. A ciência da Ginástica Artística: desafios e propostas. . In: SIMPÓSIO INTERNACIONAL DE GINÁSTICA ARTÍSTICA E RÍTMICA DE COMPETIÇÃO, 3., 2012, Rio Claro. Anais... Rio Claro: Unesp, 2012.

CARBINATTO, M.; UEZU, R.; DUARTE, L. H.; TSUKAMOTO, M. H. C.; NUNOMURA, M. Perfil dos técnicos e motivos que os levaram a atuar na ginástica artística de alto rendimento. In: SIMPÓSIO INTERNACIONAL DE GINÁSTICA ARTÍSTICA E RÍTMICA DE COMPETIÇÃO, 2., 2010, Campinas. Anais...Campinas: FEF/UNICAMP, 2010.

INSTITUTO BRASILEIRO DE GEOGRAFIA E ESTATÍSTICA (IBGE). Pesquisas de informações básicas Municipais: Perfil dos municípios brasileiros (2009). Disponível em: < http://www.ibge.gov.br/home/estatistica/economia/perfilmunic/defaulttab3 coleta.shtm> Acesso em: 8 fev. 2012.

LEMYRE, F.; TRUDEL, P.; DURAND-BUSH, N. How youth-sport coaches learn to coach. The Sport Psychologist, v. 21, p. 191-209, 2007.

LOPES, P.; NUNOMURA, M. Motivação para a prática e permanência na ginástica artística de alto nível. Rev. Bras. Educ. Fís. Esporte, São Paulo, v. 21, n. 3, p.177-87, jul./set. 2007.

NUNOMURA, M. Técnico de ginástica artística: uma proposta para a formação profissional. 2001. 181 f. Tese (Doutorado em Educação Física) -Faculdade de Educação Física, Universidade Estadual de Campinas, Campinas, 2001.

NUNOMURA, M. Lesões na Ginástica Artística: Principais incidências e medidas preventivas. Motriz. Revista de Educação Física. UNESP, Rio Claro, v. 8, n. 1, p. 21- 29, 2002.

NUNOMURA, M. A Formação dos Técnicos de Ginástica Artística: os modelos internacionais. Revista Brasileira de Ciência e Movimento, Brasília, v. 12, n. 3, p. 6369, set., 2004. 
NUNOMURA, M. ; CARRARA, P. ; CARBINATTO, M.. Reflexão sobre um programa de Formação Profissional na Ginástica Artística. Pensar a Prática, v. 16, n. 2, p. 320-618, 2013.

NUNOMURA, M.; NISTAPICCOLO, V. L. A Ginástica Artística no Brasil: Reflexões sobre a Formação Profissional. Revista Brasileira de Ciências do Esporte, Campinas, v. 24, n. 3, p.175192, maio 2003.

NUNOMURA, M.; OLIVEIRA, M.S. Centro de excelência e ginástica artística feminina: a perspectiva dos técnicos brasileiros. Motriz. Revista de Educação Física. UNESP, Rio Claro, v. 18, n. 2, p. 297- 392, 2012.

PAOLIELLO, E. A Ginástica Geral e a formação universitária. In: Anais do I Fórum Internacional de Ginástica Geral. Campinas, SP: SESC: Faculdade de Educação Física, UNICAMP, 2001.

SCHIAVON, L. M. Ginástica Artística feminina e História Oral: a formação desportiva de ginastas brasileiras participantes de Jogos Olímpicos (1980-2004). 2009. 379f. Tese (Doutorado em Educação Física) Faculdade de Educação Física. Universidade Estadual de Campinas. CampinasSP, 2009.

SCHIAVON, L .M.; PAES, R. R. Condições dos treinamentos de ginastas brasileiras participantes de jogos olímpicos (1980-2004). Motriz. Revista de Educação Física. UNESP, Rio Claro, v. 18, n. 4, p. 757- 769, 2012.

SCHIAVON, L. M.; PAES, R.R.; TOLEDO, E.; DEUTSCH,S. Panorama da ginástica artística feminina brasileira de alto rendimento esportivo: progressão, realidade e necessidades. Rev. Bras. Educ. Fís. Esporte, São Paulo, v. 27, n. 3, p. 323-32, jul./set. 2013.

THOMMAZO, A. Superando dificuldades no trato da ginástica artística na prática profissional de professores iniciantes de educação física. 2006. 132 f. Dissertação (Mestrado em Ciências da Motricidade)-Instituto de Biociências, Universidade Estadual Paulista, Rio Claro, 2006.

THOMAS, J. R.; NELSON, J. K. Métodos de pesquisa em atividade física. 3. ed. Porto Alegre: ARTMED, 2002.

TSUKAMOTO, M. H. C. . Formação e experiência de professores de ginástica artística em clubes e escolas.. In: CONGRESSO BRASILEIRO DE CI- 
ÊNCIAS DO ESPORTE (CONBRACE), 16., 2009, Salvador. Anais... Salvador, 2009.

WERTHNER, P.; TRUDEL, P. A new theoretical perspective for understanding how coaches learn to coach. The Sport Psychologist, v. 20, p. 198-212, 2006.

WILLIAMS, S. J.; KENDALL, L. Perceptions of elite coaches and sports scientists of research needs for elite coaching practice. Journal of Sports Sciences. v. 25, p. 1577-1586, 2007.

ZAKHAROV, A.; GOMES, A. C. Ciência do treinamento desportivo. 2. ed. Rio de Janeiro: Grupo Palestra Sport, 2003.

Recebido em: 24/03/2014

Revisado em: 07/05/2014

Aprovado em: 01/07/2014

Endereço para correspondência:

lauritaschi@hotmail.com

Laurita Marconi Schiavon

Universidade Estadual Paulista Júlio de Mesquita Filho, Instituto de Biociências de Rio Claro.

Av. 24 A - no. 1515 (Departamento de Educação Física)

Bela Vista

13506-900 - Rio Claro, SP - Brasil 